\title{
Post-traumatic Stress Disorder among American Legionnaires in Relation to Combat Experience in Vietnam: Associated and Contributing Factors ${ }^{1}$
}

\author{
Barry R. Snow ${ }^{*} \nmid$ Jeanne Mager Stellman, $†$ Steven D. Stellman, ${ }^{\prime 2}$ \\ AND JOHN F. SOMMER, JR.§ \\ *Department of Behavioral Medicine, Hospital for Joint Diseases, New York, New York; $†$ School \\ of Public Health, Columbia University, New York, New York; $\ddagger$ Department of Epidemiology and \\ Statistics, American Cancer Society, New York, New York; and \$National Veterans Affairs and \\ Rehabilitation Commission, The American Legion, Washington, D.C.
}

\author{
Received January 20, 1988
}

\begin{abstract}
The relationship between combat stress, DSM-III-defined post-traumatic stress disorder (PTSD), and a variety of behavioral factors was examined in a large nonclinical population. A total of 2858 randomly selected American Legion members who had served in Southeast Asia completed a questionnaire which elicited information on military service, personal health, and a variety of mental health outcomes. The data confirm the utility of the PTSD diagnosis as a distinct clinical entity. The frequency of PTSD and the extent of symptoms developed varied with the severity of criteria used for determining the extent of traumatic exposure. The PTSD rate ranged from 1.8 to $15.0 \%$ of the total sample, depending on whether "exposure" to combat was defined relatively narrowly or broadly. A distinct linear dose-response relationship between combat stress and a quantitative measure of PTSD intensity was observed. The frequency of PTSD diagnosis was not affected by the presence of either physical or mental health problems which predated military service. A strong, stable relationship was found between combat stress and PTSD intensity for cohorts with differing intervals since the experience of combat trauma, which persisted up to 20 years after discharge from the military. The data thus support a broader approach to defining traumatic events which recognizes individual differences in response to combat, as well as the existence of other behavioral outcomes as residual effects of combat. Implications of these findings and the importance of treating veterans with varying presentations of PTSD are discussed. @ 1988 Academic Press, Inc.
\end{abstract}

\section{INTRODUCTION}

The postwar adjustment of Vietnam veterans has been viewed with increased clinical and epidemiological attention in the past decade (Penk and Robinowitz, 1987). These studies estimate that approximately 20 to $25 \%$ of the $3-4$ million Vietnam veterans returned from the Vietnam War with significant signs of emotional distress (Blank, 1982; Egendorf et al., 1981). These signs of distress had been previously described in several clinical and anecdotal reports and include a variety of physical and psychological symptoms that are believed to be associated with exposure to a traumatic event.

\footnotetext{
${ }^{1}$ Address reprint requests to Foundation for Worker, Veteran, and Environmental Health, 117 St. John's Place, Brooklyn, NY 11217.

${ }^{2}$ Present address: New York City Department of Health, New York, NY 10013.
} 
To provide a framework for the understanding and treatment of post-traumatic symptoms, the Diagnostic and Statistical Manual of Mental Disorders ("DSMIII," American Psychiatric Association, 1980) formally introduced post-traumatic stress disorder (PTSD) as a clinical syndrome that may result from combat exposure and other traumatic events. As currently defined, the diagnosis of PTSD requires four criteria: (1) exposure to a traumatic event; (2) reexperiencing of the event through intrusive memories, dreams or associations; (3) decline in external involvement as shown by loss of interest in significant activities, distancing from others or constricted affect; and (4) a variety of specific physiological symptoms of distress that are not present prior to exposure to the traumatic event. These outcomes are listed in a menu fashion so that two individuals can receive a PTSD diagnosis with different types of traumatic exposure and varying symptom presentations. A recent revision of the manual (American Psychiatric Association, 1987) reaffirmed the existence of this syndrome of response to traumatic events and broadened somewhat the range of physiological and behavioral responses that may be considered symptomatic of this disorder.

Recognition of emotional and psychological distress in veterans of military combat is as old as warfare itself. Nevertheless, within the framework of modern medical practice PTSD is a fairly new clinical entity, about which many uncertainties remain, especially with regard to its extent within the veteran population and its intensity among individual soldiers. Development and allocation of treatment resources within veteran-oriented and other health and social welfare institutions depend to a considerable degree on resolving these uncertainties concerning what PTSD is and how many veterans are affected by it.

This study of combat-related stress was undertaken with four specific goals in mind. Those were to examine (1) the frequency of combat-related PTSD and its components in a large, randomly selected sample of Vietnam veterans, (2) the degree to which varying levels and definitions of combat stress influence the expression of PTSD in this sample, (3) the influence of precombat and other predisposing factors on the expression of PTSD, and (4) the stability of the PTSD symptom complex over time.

A variety of studies have been conducted to clarify the nature of the PTSD diagnosis as a discrete syndrome. These studies have confirmed the existence of PTSD symptomatology, but have also called attention to the wide variability that may exist in the manner in which PTSD is expressed. Several studies, for example, suggest that the concept of PTSD needs to be broadened to include affective responses like depression and behavioral outcomes such as aggressive behavior and anger (e.g., Silver and Iacono, 1984; Van Kampen et al., 1986). Other studies have acknowledged outcomes such as these to be combat related but have emphasized that they could be more fruitfully treated as separate conditions (Jelinek and Williams, 1984; Sierles et al., 1983, 1986). Proponents of a narrow definition of PTSD posit that the key characteristic which differentiates PTSD from other disorders is the intrusiveness of the traumatic memories associated with it (Green et al., 1985; Brett and Ostroff, 1985). Both the narrow and broadened approaches to PTSD stand in direct contrast to an interpretive approach which continues to 
view the diagnostic correlates of PTSD as a challenge to the uniqueness of PTSD as a separate clinical entity (Behar, 1987).

One way to clarify the extent to which PTSD is a distinct diagnostic entity is to differentiate PTSD symptoms from coexisting psychiatric disorders that may be present in a clinical sample of study subjects (Keane et al., 1987). A key research strategy to facilitate this process involves broadening of the study of PTSD beyond clinical samples of convenience, such as subjects who present themselves for treatment for drug or alcohol dependence. These populations may present with significant noncombat-related trauma that influences the expression of PTSD (Denny et al., 1987). The current paper examines the frequency of PTSD and other associated symptoms in a large nonclinical population. Specific information on the relative frequency and intensity of the different components of PTSD and associated behavioral outcomes can help clarify the issue of whether PTSD should be regarded as a distinct diagnostic entity.

A second focus of this study is to examine the nature of the precipitating factors that are necessary for PTSD to be experienced. A variety of clinical and experimental evidence suggests that cumulative exposure to prolonged danger as well as single episodes of extraordinary danger may both produce PTSD (Birkheimer et al., 1985; Heimberg, 1985; Keane, 1985; Saigh, 1985). These findings would be consistent with the interactionist trend of stress research which emphasizes the importance of defining trauma from the perspective of both the event and the individual (Lazarus, 1966). This approach would also allow for the development of PTSD in individuals with no unique identifiable stressor, but for whom the entire combat experience may have served as a diffuse stressor. The current study therefore examines the extent to which the frequency of PTSD diagnoses changes in relation to varying the criteria of exposure to life-threatening combat events. Examination of the presence of PTSD in differently defined exposure groups may clarify the types of situations necessary to elicit this particular response syndrome.

The etiologic roles of selected demographic and precombat health variables upon the development of PTSD constitute a third focus of our investigation. A considerable body of literature exists on the importance of predisposing factors on the nature of response to trauma. This work, largely conducted in the psychoanalytic tradition, has emphasized the role of childhood conflicts and family units where affection was not freely given as key factors in the etiology of traumatic stress symptoms (Lidz, 1946). This view of combat stress was based on the assumption that adverse combat reactions are abnormal and are associated with the individual's degree of psychopathology. Numerous case histories gathered in clinics and on the battlefields during World War II and other conflicts formed the basis of this model, which was also supported by the early research on postwar adjustment in Vietnam veterans. This research emphasized the critical importance of premilitary adjustment variables in determining later health (Nace et al., 1978; Worthington, 1978).

More recent empirical work with victims of natural disasters (Lifton and Olson, 1976) has, however, favored a severity of trauma model. This scheme emphasizes 
the extent of trauma exposure as the critical factor in PTSD development, while minimizing the role of pretrauma personality in the development of symptoms. A variety of studies, using samples of Vietnam veterans that were typically of limited size support the model (Foy et al., 1984, 1987). The present study examines the influence of selected precombat factors in a large group of Vietnam veterans from a randomly selected nonclinical population, in order to clarify the validity of the severity of trauma model.

The fourth and final goal of the study is to clarify the stability of the PTSD symptom cluster over time. Denny et al. (1987) noted that PTSD research has not fully delineated the time course of PTSD as a disorder or its durability. The existence of key changes in the expression of PTSD is suggested by the clinical work of Horowitz (1976) and others working with a variety of traumatized populations. These studies maintain that post-traumatic responses vary as a function of time and individual differences in style of information processing and the nature of the traumatic event. By assessing the presence of PTSD in veterans with different intervals from last date of service, the presentation of PTSD at different stages of the disorder can be studied.

Confirmation of the existence of PTSD several years after military service has ended would be consistent with a residual stress model of traumatic exposure, in which psychological reactions to combat are related to the severity of trauma exposure and persist beyond the period of the original traumatic event (Figley, 1978). A contrasting "stress evaporation" model maintains that stress reactions disappear soon after the individual leaves the stressful setting. This model characterized early studies of adjustment problems facing Vietnam veterans as they returned from the combat theater (Borus, 1973, 1974). The current research will examine the combat stress-PTSD linkage across different cohorts of veterans. Two alternative possibilities are considered: either the effect of unresolved stress grows stronger with time (intensification), or the relationship remains the same (persistence). No a priori preference for either of these hypotheses is offered.

This paper is part of a series of five on the health and well-being of a large nonclinical population of veterans who are members of The American Legion. Study design and methodology are presented in the first paper (Stellman et al., 1988a), while demographic characteristics of the population, and influence of combat on social and behavioral aspects are presented in the second (Stellman $e t$ al., 1988b). The two other papers deal with the health of veterans and their offspring in relation to combat and herbicide exposure (Stellman et al., 1988c), and utilization of and experiences with Veterans Administration facilities (Stellman et al., 1988d).

\section{METHODS}

\section{Overview}

In 1984, a cross-sectional survey was conducted on a sample of men who were members of The American Legion in Colorado, Indiana, Minnesota, Maryland, Ohio, and Pennsylvania. The Legionnaire sample was randomly selected from the membership roster so that sufficient numbers of men who served in Southeast 
Asia and men who served elsewhere during the same period were chosen. A total of 6810 responses were received; the response rate ranged from $58.1 \%$ in Pennsylvania to $64.6 \%$ in Minnesota. Extensive investigation revealed no discernible systematic response bias in the selection process. Further details of survey methodology have been presented in the first paper of this series (Stellman et al., 1988a).

The Southeast Asia sample that was identified through this sampling process was predominantly white, had at least a high school education, and had a median family income in the $\$ 20,000-\$ 25,000$ range. They did not differ significantly in these demographic factors from the non-Southeast Asia sample. The present paper is based on the responses of the 2858 men in the former group to a confidential questionnaire, which elicited information on dates and location of military service, personal and family health, social and behavioral characteristics and attitudes, and mental health data.

\section{Variables}

Exposure to a traumatic event. The clinical criteria for DSM-III-defined PTSD require evidence of exposure to a traumatic event and the presence of a variety of physical and psychological symptoms that are presumed to be responses to this event. The survey instrument therefore contained a series of questions designed to tap these criteria. Exposure to a traumatic event was assessed by an adaptation of the Vietnam Veterans Questionnaire measure of combat stress (Figley, 1977; Stretch and Figley, 1984). This scale is a validated method for quantifying the level of stress associated with combat experience. The scale consists of eight items relating to specific combat exposures (see Table 1). Five response categories ranging from "Never" to "Very often" are used.

The combat scale can be used as a continuous measure of combat intensity (Frye and Stockton, 1982). We have used this scale in three alternative ways as an indicator of exposure to traumatic events. These ways included (1) a median split on the total scale score, (2) a more focused criterion of frequent exposure (response of "Often" or "Very often") to any one of the eight combat events on the scale, and (3) a more stringent criterion of frequent exposure to all eight events on the combat scale. These different criteria were used to maximize the match of the

TABLE 1

Items Constituting the Combat Scale

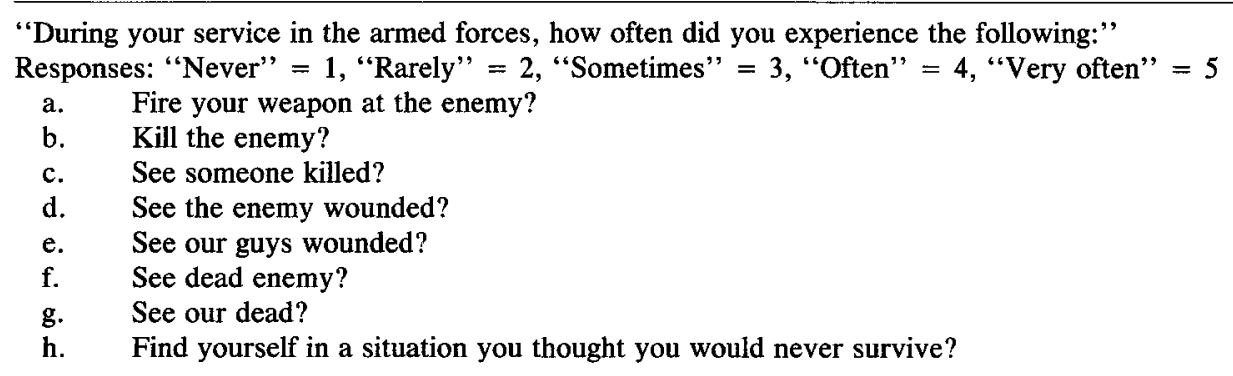


self-report instrument to the interview-based diagnostic assessment of the presence of a history of traumatic exposure (Foy et al., 1984; Roberts et al., 1982). Further information on the component items and reliability of the combat measure, as well as its distribution in the study population, is presented in the first paper of this series (Stellman et al., 1988a).

PTSD symptoms. The questionnaire contained a problem checklist designed to elicit the physical and psychological symptoms of PTSD. The PTSD symptom checklist, which was based on Figley's (1977) symptom checklist, is directly modeled after the DSM-III criteria for PTSD. For each of the 18 items on the list, subjects were asked how frequently they experienced a specific situation or feeling since discharge from the military, with five allowable responses per item ranging from "Never" to "Very often." The checklist is evaluated in a menu fashion whereby an extreme score (response of "Often" or "Very often") on a particular item is considered equivalent to a clinical assessment of the presence of that symptom (Frye and Stockton, 1982; Foy et al., 1984).

In the analyses which follow, the 18 items are grouped into three broader categories which correspond to the discrete symptom based elements of the PTSD diagnosis as prescribed by DSM-III: reexperiencing the traumatic event ( 5 items), decline in external involvement ( 6 items), and behavioral signs of distress ( 7 items). This procedure allows the global PTSD diagnosis to be broken down so that the presence of these three major PTSD components can be determined for each veteran, and their relation to combat evaluated. Finally, each symptom item is assigned an intensity score from 1 to 5 ; a continuous measure of overall PTSD intensity is then obtained by summing across all 18 PTSD symptom items (Lund et al., 1984; Foy et al., 1984).

Definition of PTSD. A diagnosis of PTSD was assigned to any veteran who met all four of the following criteria: (a) exposure to combat stress; (b) response of "Often" or "Very often" to any item in the reexperiencing of traumatic event category; (c) response of "Often" or "Very often" to any item in the decline in external involvement category; and (d) response of "Often", or "Very often" to any two items in the behavioral signs of distress category. This definition matches the DSM-III-defined diagnostic criteria. With regard to point (a), however, note that DSM-III is not quantitative, and requires the clinician to make a subjective judgment of the presence of traumatic exposure.

For the purpose of assigning a diagnosis of PTSD, subjects were classified as combat exposed or not exposed according to each of the three alternative definitions described above, taken in turn. In this way the diagnostic assignment is fully quantitative, and applied in a uniform, objective manner for each subject. It results in three different, alternative PTSD/no PTSD groupings of veterans, depending on which definition of combat is used. Since these definitions are successively more restrictive, some subjects appear in more than one group.

Behavioral symptoms. Finally, the questionnaire contained an extensive checklist of behavioral and physical health symptoms. These symptoms were based on previous large-scale surveys of healthy individuals (Caplan et al., 1975; Dohrenwend et al., 1980; Quinn and Shepard, 1974; Stellman et al., 1987). They included such symptomatic complaints as headaches, being frequently nervous, difficulty 
with memory or concentration, difficulty sleeping, poor appetite, and a variety of behavioral outcomes potentially linked to PTSD. Veterans were asked to indicate the presence or absence of each of these problems and whether these symptoms had been a problem prior to their entry into military service. Subjects were also asked whether they had had a psychiatric hospitalization or received mental health treatment as an outpatient. Several measures of affect derived from these surveys were also included. These scales were the depression, anxiety, irritation and helplessness, and physical signs of depression scales. [An extensive analysis of behavioral scales derived from these items was presented in the second paper of this series (Stellman et al., 1988b).]

\section{RESULTS}

An initial analysis examined the frequency of DSM-III-defined PTSD in this nonclinical sample of Vietnam veterans. Table 2 shows the frequencies of the final diagnosis of PTSD for the American Legion veterans, using the three previously defined alternative criteria for exposure to traumatic combat stress. The frequency of PTSD and its symptom components varies according to the severity of the criterion used for determining traumatic exposure. When the strictest criteria of a frequent exposure to all items on the combat stress scale are used, only a small percentage of American Legion veterans (1.8\%) are diagnosed as having PTSD. This low figure reflects the infrequency of endorsement (only 2.7\%) of high levels of exposure to all eight items. The least restrictive definition of combat stress, that used the median split criterion to classify exposure, placed 1524 of 2845 individuals $(53.6 \%)$ into the high-exposure group, and resulted in a diagnosis of PTSD for 429 of them (15.0\%).

The next set of analyses examined the prevalence of specific symptoms, as measured by the frequency of endorsement of the "Often" and "Very often" choices (Table 3). Intensities of the individual items, as measured by their mean scores, were compared in the same way (Table 4). The individual PTSD symptoms varied in both frequency and intensity as a function of the exposure criteria used. When high levels of exposure to all eight combat events were required for

TABLE 2

Effect of Alternative Definitions of Exposure to Combat Stress on Diagnosis of PTSD

\begin{tabular}{|c|c|c|}
\hline $\begin{array}{l}\text { Definition of exposure } \\
\text { to combat stress }\end{array}$ & $\begin{array}{l}\text { Number of men exposed, } \\
\text { according to this } \\
\text { definition }\end{array}$ & $\begin{array}{c}\text { Number of men with PTSD } \\
\text { according to this } \\
\text { definition }^{a}\end{array}$ \\
\hline Median or above & $1524(53.6 \%)$ & $429(15.0 \%)$ \\
\hline $\begin{array}{l}\text { Exposure to one or more combat } \\
\text { events }^{b}\end{array}$ & $1164(40.7 \%)$ & $359(12.6 \%)$ \\
\hline $\begin{array}{l}\text { Exposure to all eight combat } \\
\text { events }^{b}\end{array}$ & $78 \quad(2.7 \%)$ & $51 \quad(1.8 \%)$ \\
\hline
\end{tabular}

a PTSD diagnosis according to DSM-III criteria, as described in the text, using given definition of exposure to combat stress.

$b$ "Exposure" means a response of "Often" or "Very often" to indicated number of combat questionnaire items. 
TABLE 3

Percentage of Men Checking "Often" or "Very Often" to Individual PTSD COMPONENT ITEMS, ACCORDING TO COMBAT EXPOSURE

\begin{tabular}{lccc}
\hline & \multicolumn{3}{c}{ Definition of combat exposure $^{\text {Exposure }}$} \\
\cline { 2 - 4 } & $\begin{array}{c}\text { Combat } \\
\text { median or } \\
\text { above }\end{array}$ & $\begin{array}{c}\text { Exposure } \\
\text { to one or more } \\
\text { combat events }\end{array}$ & $\begin{array}{c}\text { Exp } \\
\text { to all eight } \\
\text { combat events }\end{array}$ \\
\hline $\begin{array}{l}\text { Number of subjects meeting this } \\
\text { definition: }\end{array}$ & 1523 & 1162 & 78 \\
Clinical diagnosis of PTSD & & & \\
PTSD component category & 28.2 & 30.9 & 65.4 \\
Reexperiencing of traumatic event & & & \\
Had vivid recollections & 25.2 & 30.0 & 55.8 \\
Had dreams or nightmares & 17.0 & 20.8 & 50.0 \\
Thought about service unexpectedly & 33.1 & 35.5 & 57.7 \\
Felt like back in service & 10.1 & 11.6 & 30.8 \\
Reminded by things of service & 55.0 & 57.6 & 84.6 \\
Decline in external involvement & & & \\
Felt not worth getting close & 30.8 & 32.8 & 51.3 \\
Felt needed people less & 33.4 & 35.7 & 53.2 \\
Worried about keeping your interest & 17.6 & 18.3 & 43.6 \\
Felt like shutting out world & 28.2 & 30.5 & 51.3 \\
Found unable to feel emotions & 26.1 & 27.2 & 42.1 \\
Had don't give a damn attitude & 29.6 & 31.9 & 51.9 \\
Behavioral signs of distress & & & \\
Couldn't tolerate being startled & 25.3 & 26.8 & 55.8 \\
Had trouble sleeping & 24.3 & 27.9 & 58.4 \\
Felt guilty about surviving & 10.5 & 11.3 & 31.2 \\
Had a tough time completing projects & 13.2 & 13.8 & 26.0 \\
Nervous when reminded of service & 16.7 & 18.4 & 37.7 \\
Avoided topic of service & 30.0 & 31.8 & 48.1 \\
Worried over temper & 30.9 & 31.9 & 59.2 \\
\hline
\end{tabular}

a Response of "Often" or "Very often" to indicated number of combat events.

${ }^{b}$ Based on DSM-III criteria, except that combat stress is defined as shown in column heading.

the presumption of traumatic exposure (column 3 of either table), more individuals so exposed endorsed the symptom items, and higher mean scores on the intensity scales were attained.

The high levels of endorsement for the entire range of PTSD symptoms stand in contrast to the lower levels under the more focused PTSD definition requiring frequent exposure to a specific item on the combat stress scale (column 2) or the alternatively defined grouping based on an above-median score on the combat stress scale (column 1). These two groupings moreover exhibited similar levels of endorsement for many of the PTSD symptom items, and were well below the levels seen under the most restrictive combat definition. The patterns for means were similar to those for the frequencies. For every item, the mean score was highest when exposure was defined most strictly (frequent endorsement of all eight combat events), and lower for combat defined as exposure to one or more 
TABLE 4

Mean Values of PTSD Component Items According to Combat Exposure

\begin{tabular}{lccc}
\hline & \multicolumn{3}{c}{ Definition of combat exposure } \\
\cline { 2 - 4 } & $\begin{array}{c}\text { Combat } \\
\text { median or } \\
\text { above }\end{array}$ & $\begin{array}{c}\text { Exposure } \\
\text { to one or more } \\
\text { combat events }\end{array}$ & $\begin{array}{c}\text { Exposure } \\
\text { to all eight } \\
\text { combat events }\end{array}$ \\
\hline $\begin{array}{l}\text { Number of subjects meeting this } \\
\text { definition: }\end{array}$ & 1523 & 1162 & 78 \\
Clinical diagnosis of PTSD & & Mean & \\
Reexperiencing of traumatic event & 48.85 & 49.67 & 62.21 \\
Had vivid recollections & & & \\
Had dreams or nightmares & 3.01 & 3.09 & 3.78 \\
Thought about service unexpectedly & 2.68 & 2.75 & 3.64 \\
Felt like back in service & 3.18 & 3.23 & 3.73 \\
Reminded by things of service & 2.25 & 2.32 & 2.99 \\
Decline in external involvement & 3.57 & 3.61 & 4.38 \\
Felt not worth getting close & & & 3.56 \\
Felt needed people less & 2.85 & 2.91 & 3.53 \\
Worried about keeping your interest & 2.84 & 2.89 & 3.31 \\
Felt like shutting out world & 2.46 & 2.48 & 3.47 \\
Found unable to feel emotions & 2.73 & 2.79 & 3.42 \\
Had don't give a damn attitude & 2.71 & 2.73 & 3.60 \\
Behavioral signs of distress & 2.98 & 3.04 & 3.63 \\
Couldn't tolerate being startled & & & 3.74 \\
Had trouble sleeping & 2.68 & 2.72 & 2.75 \\
Felt guilty about surviving & 2.76 & 2.83 & 2.86 \\
Had a tough time completing projects & 1.92 & 1.94 & 3.27 \\
Nervous when reminded of service & 2.37 & 2.38 & 3.38 \\
Avoided topic of service & 2.45 & 2.48 & 3.72 \\
Worried over temper & 2.81 & 2.85 & \\
\hline
\end{tabular}

${ }^{a}$ Response of "Often" or "Very often" to indicated number of combat events.

${ }^{b}$ Based on DSM-III criteria, except that combat stress is defined as shown in column heading.

events, as well as when exposure was taken as any combat score at or above the median. The mean PTSD total intensity score also displayed this pattern. [Indeed, further analyses which defined combat stress in yet another way (as frequent exposure to three or more combat events) revealed an intermediate pattern of outcomes.]

The frequency of endorsement as well as mean score values for the individual PTSD items vary markedly for the different PTSD symptoms. Items dealing with the intrusiveness of combat experience, such as being reminded by things of the service and thinking about the service unexpectedly, have a somewhat higher frequency of endorsement and higher mean value for all three combat group definitions. The lowest frequency of endorsement, and lower mean values, on the other hand, are for miscellaneous items like survival guilt, having a tough time completing projects, and physiologic reactivity upon exposure to events that remind them of the service.

The mean levels of occurrence of a variety of social, familial, and behavioral 
mental health outcomes were next considered. Table 5 shows the mean levels of these items for the groups that are diagnosed as having PTSD using the three varying definitions of traumatic combat exposure. This table shows that all three high combat groups have comparable levels of life disruption despite these different definitions. All these factors are moreover distributed significantly differently from the non-PTSD group $(P<0.001)$. The only factor in which the groups differ somewhat from each other is in the physical signs of depression scale where the subgroup with the most stringent requirement for combat exposure scored highest. These consistent similarities in familial and behavioral outcomes for groups that differ markedly in degree of combat exposure stand in direct contrast to the differences between the same groups with respect to PTSD symptoms. These comparisons show that merely changing the definition of combat does not automatically lead to changes in other, non-PTSD-related outcomes, and therefore provide further support for the clinical uniqueness of the symptom items that constitute the diagnosis of PTSD.

Tables 3 and 4 also address the second hypothesis concerning whether a diffuse stressor can be associated with the development of PTSD. The top-most row of both tables shows roughly similar levels of PTSD whether a median-split approach is used that classifies high scorers by overall amount of exposure to a variety of combat events or a more focused approach that requires a high degree of exposure

TABLE 5

Mean Values for Social, Familial and Mental Health Outcomes According to COMBAT EXPOSURE

\begin{tabular}{lccc}
\hline & \multicolumn{3}{c}{ Definition of combat exposure } \\
\cline { 2 - 4 } & $\begin{array}{c}\text { Combat } \\
\text { median or } \\
\text { above }\end{array}$ & $\begin{array}{c}\text { Exposure } \\
\text { to one or more } \\
\text { combat events }\end{array}$ & $\begin{array}{c}\text { Exposure } \\
\text { to all eight } \\
\text { combat events }^{a}\end{array}$ \\
\hline Number of subjects: & 1523 & 1162 & 78 \\
Scale item & & & \\
How helpful was your family & 2.69 & 2.69 & 2.59 \\
How easy to talk to & 4.10 & 4.16 & 4.51 \\
How supportive was community & 3.67 & 3.68 & 3.62 \\
How satisfied with spouse & 1.99 & 1.96 & 1.96 \\
Spouse's satisfaction with subject & 2.14 & 2.11 & 1.91 \\
How satisfied with being parent & 2.23 & 2.20 & 2.07 \\
How happy are you now & 2.48 & 2.48 & 2.42 \\
How satisfied with life & 2.45 & 2.45 & 2.50 \\
Sex scale & 10.75 & 10.72 & 11.33 \\
Marital & 21.72 & 21.90 & 21.47 \\
Parent & 14.85 & 14.77 & 14.50 \\
Depression & 12.39 & 12.58 & 12.48 \\
Anxiety & 13.43 & 13.50 & 13.53 \\
Helplessness & 10.08 & 10.24 & 10.74 \\
Irritation & 13.87 & 13.89 & 13.62 \\
Physical signs of depression & 7.00 & 7.10 & 8.48 \\
\hline
\end{tabular}

a Response of "Often" or "Very often" to indicated number of combat events.

${ }^{b}$ Defined more fully in Stellman et al. (1988b). 
to at least one combat experience. These findings argue against the need to find a specific traumatic event associated with PTSD. Although the higher combat groups, however defined, clearly show the preponderance of symptoms, and exhibit a higher rate of clinical PTSD, the consistent endorsement of some PTSD symptoms in each corresponding low-combat group, and the small but consistent levels of clinical PTSD, provide additional support for the concept that PTSD can develop in response to diffuse stressors. Table 6 shows this point even more clearly. It documents frequent endorsement of a high level of at least one symptom from each of the three major categories of PTSD symptoms for the variously defined high- and low-combat groups. Approximately $30 \%$ of the veterans designated as having low combat exposure admitted to at least one post-traumatic symptom of reexperiencing the event, and one symptom of decline in external involvement. Furthermore, a noteworthy minority of subjects in each combatdefined subgroup $(7.6,10.2$, and $17.3 \%$ ) had enough symptoms in all three PTSD categories to have received a clinical diagnosis of PTSD had they also fulfilled the criterion of exposure to combat stress. Additional analyses focusing on the small group of subjects $(N=449)$ who had infrequent exposure to combat events, but whose combat scores were still above the median, similarly showed high rates $(52.6,45.9$, and $48.3 \%)$ of the three post-traumatic stress components listed in Table 6. These results add further support to the relationship between diffuse stressors and the PTSD outcome.

Next, the third hypothesis relating to the influence of precombat factors in producing PTSD symptoms was examined. There were no significant differences between subjects diagnosed with PTSD compared to those without PTSD in their reports of whether a variety of physical and mental health complaints existed before their entry into military service. This absence of preexisting problems held true irrespective of which of the three definitions of combat exposure was used.

TABLE 6

Percentage of Veterans Who Experienced Each of the Three Major Categories of PTSD Symptoms, as Well as PTSD ITSELF, According to Combat EXPOSURE

\begin{tabular}{|c|c|c|c|c|c|c|}
\hline & \multicolumn{6}{|c|}{ Definition of combat exposure } \\
\hline & \multicolumn{2}{|c|}{$\begin{array}{l}\text { Combat } \\
\text { median or } \\
\text { above }\end{array}$} & \multicolumn{2}{|c|}{$\begin{array}{l}\text { Exposure } \\
\text { to one or more } \\
\text { combat events }\end{array}$} & \multicolumn{2}{|c|}{$\begin{array}{c}\text { Exposure }^{a} \\
\text { to all eight } \\
\text { combat events }\end{array}$} \\
\hline & No & Yes & No & Yes & No & Yes \\
\hline Number of subjects: & \multicolumn{6}{|c|}{ Percentage } \\
\hline PTSD component category & & & & & & \\
\hline Reexperiencing of traumatic event & 31.5 & 66.3 & 36.5 & 69.8 & 48.9 & 92.3 \\
\hline Decline in external involvement & 31.6 & 55.6 & 34.9 & 58.2 & 43.3 & 84.6 \\
\hline Behavioral signs of distress & 12.2 & 37.1 & 15.6 & 39.8 & 24.2 & 69.2 \\
\hline All three & 7.6 & $28.1^{b}$ & 10.2 & $30.8^{b}$ & 17.3 & $65.4^{b}$ \\
\hline
\end{tabular}

\footnotetext{
${ }^{a}$ Response of "Often" or "Very often" to indicated number of combat events.

${ }^{b}$ Clinical diagnosis of PTSD.
} 
The self-reported rates of physical symptoms were typically under $5 \%$ for both the non-PTSD and PTSD groups. The only physical symptoms where material differences occurred were for colds or sore throats and sinus conditions, with the PTSD subjects less frequently reporting a history of prior symptoms than the non-PTSD ones.

With regard to mental health items, the veterans were also generally symptomfree prior to military service. Men with PTSD did not differ significantly from men without PTSD in the presence or absence of a major problem with depression, anxiety, or other mental health concerns prior to service. Average rates of occurrence for these problems were generally under $13 \%$ for all the groups and usually were as low as $7 \%$. The veterans reported similarly low rates for more objective data, such as frequency of psychiatric hospitalization and outpatient treatment for mental health problems. These data, shown in Table 7, demonstrate comparatively rare usage of mental health services prior to military service by all the PTSD and non-PTSD groups. Higher levels of postdischarge usage of both outpatient and inpatient mental health services are reported by the PTSD groups, with the highest rate being reported by the group with PTSD whose criteria for combat stress required high level of exposure to all combat events. [In a separate paper in this series, we examine in detail the patterns of usage of Veterans Administration mental health facilities in relation to combat experience and other demographic factors (Stellman $e t$ al., 1988d).]

The relationship between the intensity of PTSD symptoms using all the items on the scale and the level of combat stress was also investigated. Figure 1 shows the relationship for the entire sample. A strong linear relationship, in which $\rho=0.50$, $P<0.001$, was obtained. This dose-response relationship was observed with quantified scales for both combat stress and PTSD symptom intensity. This finding, together with the previously discussed findings on the minimal existence of

TABLE 7

Comparative Frequency of Psychiatric Hospitalization and OutPatient Treatment for VARIOUSLY DEFINED PTSD AND NON-PTSD GROUPS

\begin{tabular}{|c|c|c|c|c|c|c|}
\hline \multirow[b]{3}{*}{ PTSD $^{b}$} & \multicolumn{6}{|c|}{ Definitions of combat stress } \\
\hline & \multicolumn{2}{|c|}{$\begin{array}{l}\text { Combat median } \\
\text { or above }\end{array}$} & \multicolumn{2}{|c|}{$\begin{array}{l}\text { Exposure }^{a} \\
\text { to one or more } \\
\text { combat events }\end{array}$} & \multicolumn{2}{|c|}{$\begin{array}{c}\text { Exposure }^{a} \\
\text { to all eight } \\
\text { combat events }\end{array}$} \\
\hline & Yes & No & Yes & No & Yes & No \\
\hline Psychiatric hospitalization & \multicolumn{6}{|c|}{ Percentage } \\
\hline Never & 87.3 & 97.6 & 80.4 & 96.3 & 85.1 & 97.6 \\
\hline After service & 12.5 & 2.2 & 19.6 & 3.4 & 14.6 & 2.1 \\
\hline Preservice & 0.2 & 0.3 & 0.0 & 0.3 & 0.3 & 0.3 \\
\hline \multicolumn{7}{|l|}{ Outpatient treatment } \\
\hline Never & 61.4 & 86.8 & 54.9 & 83.5 & 58.9 & 86.5 \\
\hline After service & 38.3 & 12.8 & 45.1 & 16.1 & 40.8 & 13.1 \\
\hline Preservice & 0.2 & 0.4 & 0.0 & 0.4 & 0.3 & 0.4 \\
\hline
\end{tabular}

"Response of "Often" or "Very often" to indicated number of combat events.

${ }^{b}$ Based on DSM-III criteria, except that combat stress is defined as shown in column heading. 


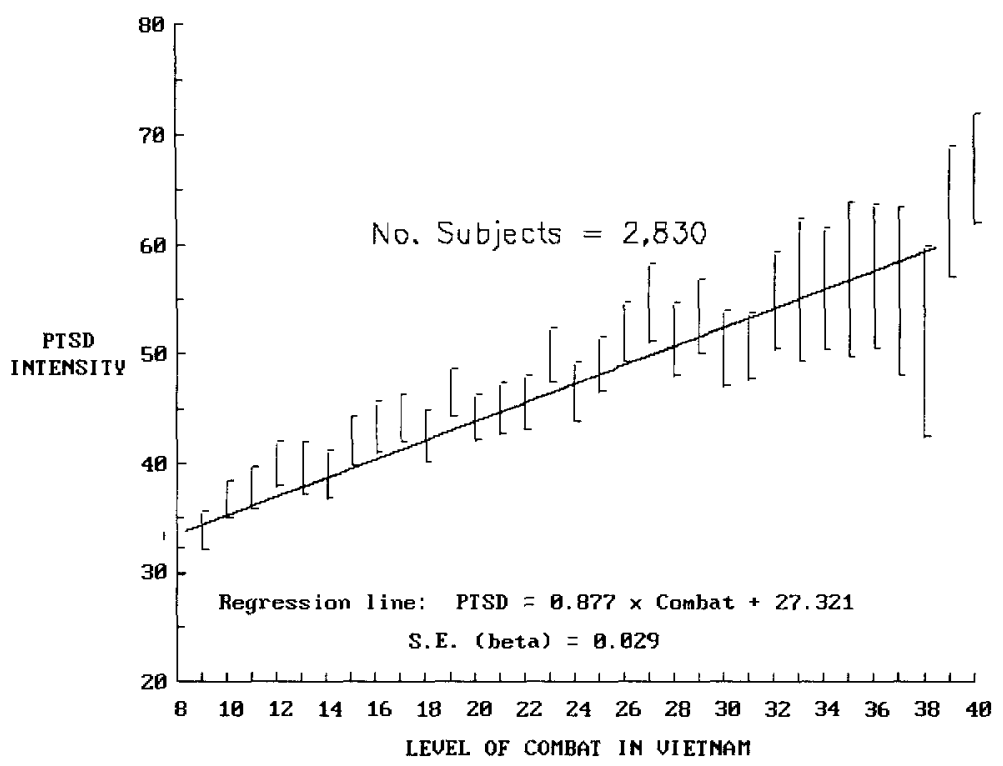

FIG. 1. PTSD vs combat. Average PTSD intensity score (sum of 18 PTSD symptom items) as a function of combat score (sum of 8 combat items), showing $95 \%$ confidence intervals and regression line.

precombat levels of physical and psychological dysfunction, strongly support the severity of trauma model.

Finally, the fourth hypothesis relating to the stability of PTSD as an outcome associated with combat stress was examined. Figure 2 shows the relationship between PTSD symptoms and combat stress for different intervals since combat trauma was experienced. These intervals were computed using 1984, the year the questionnaire was completed, as the endpoint. As shown in Fig. 2, the relationship between combat stress and PTSD is both consistent and stable over time. This stability is present despite the varying $N$ 's for the different intervals in the Legion sample. The durability of the relationship between combat stress and PTSD was further confirmed by a stepwise regression done on PTSD using combat stress and years since discharge as the independent variables. This analysis was highly significant for combat $(t=30.381, P<0.001)$ and not significant for years since discharge.

The patterns of symptom presentation across these cohorts were also investigated. These analyses focused on the mean level of the symptom endorsements for the three major categories of PTSD symptoms. The results, given in Table 8, show consistent levels in all three symptom groups for each of the cohorts indicating that individual PTSD symptoms as well as overall PTSD levels maintain the same intensity over time.

\section{DISCUSSION}

The current research provides strong evidence for the existence of PTSD in a large nonclinical sample of Vietnam veterans. Symptoms were most likely to 


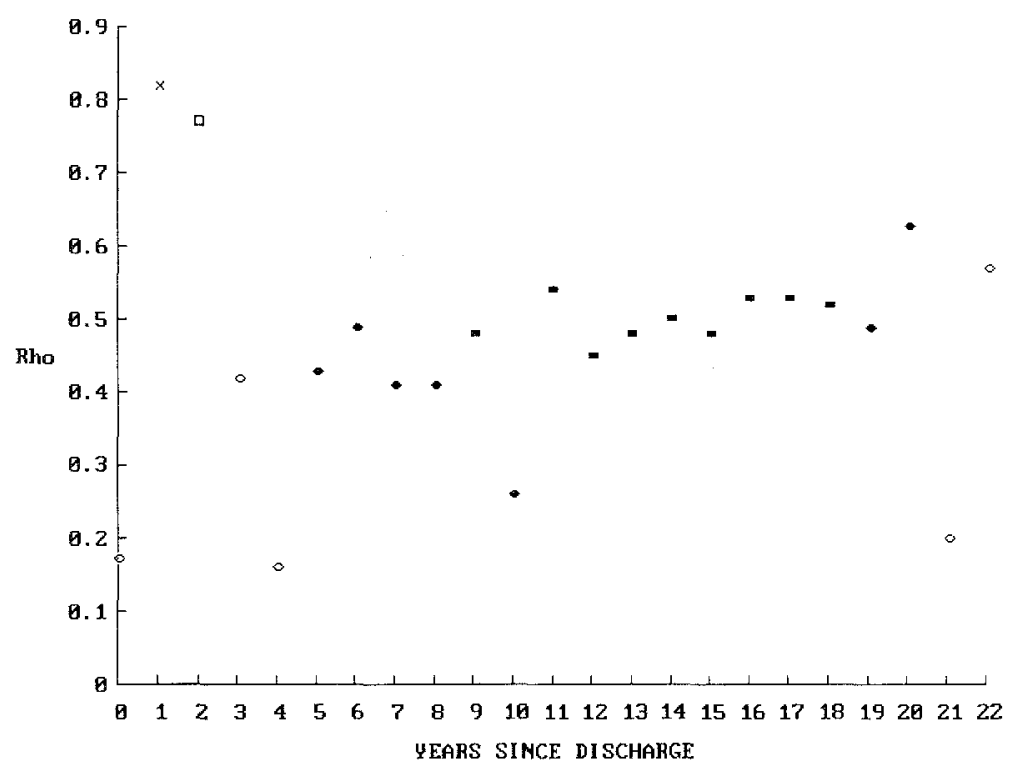

FIG. 2. Persistence of PTSD. Pearson correlation coefficient ( $\rho$ ) for relationship between PTSD intensity score and combat score, by number of years since discharge from military service. (Open circles, not significant; $X, P<0.05$; filled circles, $P<0.01$; filled squares, $P<0.001$.)

occur in individuals who had higher levels of traumatic combat exposure, and were more likely to be affective and behavioral symptoms reflecting the intrusiveness of the combat experience in their daily lives. Indeed, a clear linear dose-response relationship between combat exposure and PTSD intensity was found. These findings are thus consistent with and extend the previously cited work on the centrality of intrusive recollections in the response to traumatic conflict. The conclusions are further strengthened by the fact that the data were obtained in a systematic, objective manner using previously validated methodologies for assessment of both combat exposure and resultant stress. The data thus provide a strong complement to the clinical data gathered in face to face interviews by other investigators.

The incidence of PTSD and the likelihood of the development of the full DSMIII symptom pattern vary with the stringency of the criteria used for defining the presence of traumatic exposure. When the most severe, and infrequently occurring, criterion of exposure to all eight traumatic combat events is used, PTSD is a highly likely outcome among those meeting the criteria. However, only small numbers of veterans reported such extreme exposure. Broadening the exposure criteria potentially allows more individuals to be diagnosed as having PTSD, but reduces the percentage of people in this larger exposed group who will go on to develope the fully defined DSM-III PTSD syndrome. This finding suggests that clinical studies which report different rates of PTSD should pay more specific attention to the decision-making criteria used to determine the final diagnosis of PTSD. Adjustment of these criteria in recognition of individual differences in response to combat directly changes the frequency with which PTSD is diagnosed.

The current research also clarifies the role of other psychiatric conditions in 
TABLE 8

Mean level of Major Component Categories of PTSD Symptoms for Cohorts with DifFERING INTERVALS SINCE DisCHARGE

\begin{tabular}{cccccc}
\hline $\begin{array}{c}\text { Years } \\
\text { since } \\
\text { discharge }\end{array}$ & $\begin{array}{c}\text { No. } \\
\text { of } \\
\text { subjects }\end{array}$ & $\begin{array}{c}\text { Reexperiencing } \\
\text { of traumatic } \\
\text { event }\end{array}$ & $\begin{array}{c}\text { Decline in } \\
\text { external } \\
\text { involvement }\end{array}$ & $\begin{array}{c}\text { Behavioral } \\
\text { signs of } \\
\text { distress }\end{array}$ & $\begin{array}{c}\text { Total } \\
\text { PTSD } \\
\text { intensity }\end{array}$ \\
\hline 1 & 6 & 10.8 & 11.0 & 14.8 & 34.2 \\
2 & 11 & 15.3 & 18.0 & 17.5 & 50.8 \\
3 & 14 & 11.7 & 14.1 & 13.4 & 39.2 \\
4 & 17 & 13.7 & 14.7 & 14.2 & 42.6 \\
5 & 22 & 13.8 & 15.5 & 17.0 & 46.3 \\
6 & 27 & 13.6 & 14.9 & 17.0 & 45.4 \\
7 & 34 & 14.5 & 15.8 & 15.6 & 46.0 \\
8 & 44 & 12.4 & 13.2 & 13.8 & 38.7 \\
9 & 61 & 12.5 & 14.8 & 15.0 & 42.4 \\
10 & 90 & 12.8 & 13.7 & 14.5 & 40.9 \\
11 & 104 & 12.8 & 14.6 & 15.2 & 42.6 \\
12 & 186 & 13.0 & 14.7 & 16.2 & 43.7 \\
13 & 418 & 13.1 & 14.8 & 15.8 & 43.6 \\
14 & 492 & 13.2 & 15.2 & 16.1 & 44.4 \\
15 & 443 & 13.4 & 15.2 & 16.1 & 44.6 \\
16 & 387 & 13.3 & 15.7 & 16.5 & 45.5 \\
17 & 274 & 12.4 & 14.4 & 15.4 & 42.0 \\
18 & 134 & 11.5 & 13.8 & 14.3 & 39.4 \\
19 & 39 & 10.1 & 12.2 & 12.9 & 34.6 \\
20 & 23 & 12.0 & 11.7 & 13.3 & 36.3 \\
21 & 9 & 12.1 & 14.8 & 13.9 & 40.8 \\
22 & 8 & 11.0 & 13.5 & 12.4 & 36.9 \\
\hline
\end{tabular}

individuals who have suffered traumatic exposure. Specifically, these findings suggest that exposure to a certain level of traumatic stress may be sufficient to trigger depression or other behavioral outcomes. Whether PTSD is developed may, however, depend on the severity and frequency of the traumatic exposure. Recall that only the PTSD symptoms and not other behavioral factors were found to vary between the more moderate and extreme combat groups. These findings suggest that the PTSD concept is a unique clinical entity which need not be expanded or discarded. Rather, combat veterans may present with the intrusive symptoms of PTSD and a whole range of other affective and behavioral outcomes. The independent existence of these other conditions does not appear to detract from the existence of PTSD. Rather, each of these symptoms needs to be individually treated as part of a comprehensive treatment plan. Indeed, DSM-III guidelines have consistently urged the examining clinician to make multiple diagnoses when necessary to describe the patient's current condition (American Psychiatric Association, 1980, 1987).

The finding that some PTSD symptoms as well as a low rate of clinical PTSD occur in veterans with low levels of combat exposure suggests that despite the high correlation between combat stress and PTSD intensity, combat situations that elicit PTSD may not be totally quantifiable in a manner that could allow consistent predictions of their impact to be made. Rather, a more interactionist 
approach should be used that considers the type of symptoms expressed and the significance of the trauma that the individual believes has been experienced. This interpretation could also account for the finding of comparable rates of PTSD when combat stress was defined either using the more diffuse median split criterion or the more focused one requiring a high level of exposure to at least one combat event.

The finding of PTSD-like symptoms in veterans not considered exposed to heavy combat (Table 6) further underscores the importance of considering diffuse stressors in addition to readily identifiable traumatic exposures in the development of these symptoms. It may also reflect to some extent individual variability in response to such stressors. The existence of these symptoms in a nonclinical population of Vietnam veterans would, unfortunately, probably be unrecognized in most clinical as well as research efforts. It may in fact be the inherent confidentiality of the questionnaire process and the fraternal bonds of the American Legion system that enabled the current study to document the report of individual symptoms that in conjunction with each other would produce a clinical diagnosis of PTSD.

The consistent finding that veterans with PTSD do not differ in their report of preservice physical or mental symptoms or preservice utilization of mental health services is also worthy of note. This finding is consistent with recent trends toward minimizing the role of precombat factors in the development of PTSD. The data are also consistent with the strong relationship between PTSD intensity and level of combat exposure. One must, however, note that our questionnaire and the study as a whole focused on the current health of American Legion veterans and did not therefore contain exhaustive items on their preservice school, family, and social history. The data on preservice symptoms were moreover retrospectively obtained and subject to self-reporting bias. This bias, however, did not result in significantly different levels of admission to preservice problems by the PTSD and non-PTSD groups. This lack of difference helps strengthen confidence in the self-report data, and therefore in the validity of the severity of the trauma model rather than the pretrauma personality model in determining PTSD.

The data on PTSD persistence (Table 8 and Fig. 2) argue strongly in favor of the residual stress model of traumatic exposure, and are consistent with research that emphasizes the persistence of PTSD symptoms well beyond that combat experience and the individual's return to civilian life. Taken as a whole, these findings strengthen one's confidence in the notion of PTSD as a discreet diagnostic entity that is related to combat stress and that persists without appropriate treatment.

The current paper thus points to yet another way in which combat experience has a profound impact on the lives of veterans. Previous papers in this series have reported the impact of combat on a wide range of life experiences. These included such demographic parameters as income, divorce and marital and personal satisfaction, and such physical outcomes as ulcers, hypertension, and sebaceous cysts. This paper documents the development of PTSD and associated behavioral outcomes. Indeed, the evidence presented for moderate levels of PTSD symptoms even in veterans with low levels of combat exposure calls attention to the importance of this syndrome as a residual effect of the combat exposure. 
In a broader vein, the current research calls attention to the flexibility that intervention programs must have for the successful treatment of PTSD. Because the degree and range of PTSD symptoms may vary as a function of combat experience, veterans may not present with the full range of the disorder or not report having had intensive combat experiences. These individuals may sometimes be regarded as exaggerating their symptoms or using the diagnosis of PTSD instead of a different noncompensable psychiatric diagnosis. The current study suggests that greater clinical sensitivity to the potential variety of PTSD symptoms can aid the identification of these individuals and the design of appropriate intervention programs.

\section{REFERENCES}

American Psychiatric Association (1980). "Diagnostic and Statistical Manual of Mental Disorders," 3rd ed. Washington, DC.

American Psychiatric Association (1987). "Diagnostic and Statistical Manual of Mental Disorders." 3rd ed.-rev. Washington, DC.

Behar, D. (1987). Flashbacks and posttraumatic stress symptoms in combat veterans. Compr. Psychiatry 28, 459-466.

Birkheimer, L. S., DeVare, C. L., and Muniz, C. E. (1985). Posttraumatic stress disorder: Characteristics and pharmacological response in the veteran population. Compr. Psychiatry 26, 304-310.

Blank, A. (1982). Apocalypse terminable and interminable: Operation Outreach for Vietnam veterans. Hosp. Community Psychiatry 33, 713-718.

Borus, J. F. (1973). Reentry. I. Adjustment issues facing the Vietnam returnee. Arch. Gen. Psychiatry 28, 501-506.

Borus, J. F. (1974). Incidence of maladjustment in Vietnam returnees. Arch. Gen. Psychiatry 30 , 554-557.

Brett, E. A., and Ostroff, E. (1985). Imagery and post-traumatic stress disorder: An overview. Amer. J. Psychiatry 142, 417-424.

Caplan, R. D., Cobb, S., French, J. R. P., Van Harrison, R. V., and Pinneau, S. R. (1975). "Job Demands and Worker Health." Institute for Social Research, Ann Arbor, MI.

Denny, N., Robinowitz, R., and Penk, W. (1987). Conducting applied research on Vietnam combatrelated post-traumatic stress disorder. J. Clin. Psychol. 43, 56-66.

Dohrenwend, B. P., Shrout, P. E., Egri, G., and Mendelsohn, F. S. (1980). Non-specific psychological distress and other dimensions of psychopathology: Measures for use in the general population. Arch. Gen. Psychiatry 37, 1229-1235.

Egendorf, A., Kadushin, C., Laufer, R. S., Rothbart, G., and Sloan, L. (1981). "Legacies of Vietnam: Comparative Adjustment of Veterans and their Peers." Center for Policy Research, New York.

Figley, C. R. (1977). "American Legion Study of Psychological Adjustment of Veterans Among Vietnam Veterans." Purdue University, Lafayette, IN.

Figley, C. R. (1978). Psychological adjustment among Vietnam veterans. In "Stress Disorders among Vietnam Veterans: Theory, Research and Treatment" (C. R. Figley, Ed.). Brunner/Mazel, New York.

Foy, D. W., Carroll, E. M., and Donahoe, C. P. (1987). Etiological factors in the development of PTSD in clinical samples of Vietnam combat veterans. J. Clin. Psychol. 43, 17-27.

Foy, D. W., Sipprelle, R. C., Rueger, D. B., and Carroll, E. M. (1984). Etiology of posttraumatic stress disorder in Vietnam veterans: Analysis of premilitary, military, and combat exposure influences. J. Consult. Clin. Psychol. 52, 79-87.

Frye, J. S., and Stockton, R. A. (1982). Discriminant analysis of post-traumatic stress disorder among a group of Vietnam veterans. Amer. J. Psychiatry 139, 52-56.

Green, B. L., Lindy, J. I., and Grace, M. C. (1985). Posttraumatic stress disorder: Toward DSM-IV. J. Nerv. Ment. Dis. 173, 406-411.

Heimberg, R. G. (1985). What makes traumatic stress traumatic? Behav. Ther. 16, 417-419. 
Hendin, H., Haas, A. P., Singer, P., Gold, F., and Trigos, G. G. (1983). The influence of precombat personality on posttraumatic stress disorder. Compr. Psychiatry 24, 530-534.

Horowitz, M. J. (1976). "Stress Response Syndromes." Aronson, New York.

Jelinek, J. M., and Williams, T. (1984). Posttraumatic stress disorder and substance abuse in Vietnam combat veterans: Treatment problems, strategies, and recommendations. J. Subs. Abuse Treat. 1, 87-97.

Keane, T. M. (1985). Defining traumatic stress: Some comments on the current terminological confusion. Behav. Ther. 16, 419-423.

Keane, T. M., Wolfe, S., and Taylor, K. T. (1987). Post-traumatic stress disorder: Evidence for diagnostic validity and methods of psychological assessment. J. Clin. Psychol. 43, 32-43.

Lazarus, R. S. (1966). "Psychological Stress and the Coping Process." McGraw-Hill, New York.

Lidz, T. (1946). Nightmares and the combat neurosis. Psychiatry 3, 37-49.

Lifton, R. J., and Olson, E. (1976). The human meanings of total disaster: The Buffalo Creek Experience. Psychiatry 39, 1-18.

Lund, M., Fry, D., Sipprelle, C., and Strachan, A. (1984). The combat exposure scale: A systematic assessment of trauma in the Vietnam war. J. Clin. Psychol. 40, 1323-1328.

Nace, E. P., O'Brien, C. P., Mintz, J., Ream, N., and Meyers, A. L. (1978). Adjustment among Vietnam veteran drug users two years post service. In "Stress Disorders among Vietnam Veterans: Theory, Research and Treatment." (C. R. Figley, Ed.). Brunner/Mazel, New York.

Penk, W., and Robinowitz, R. (1987). Post-traumatic stress disorders among Vietnam veterans: Introduction. J. Clin. Psychol. 43, 56-66.

Quinn, R., and Shepard, L. J. (1974). "The 1972-73 Quality of Employment Survey." University of Michigan Survey Research Center, Ann Arbor.

Roberts, W. R., Penk, W. E., Gearing, M. L., Robinowitz, R., Dolan, M. P., and Patterson, E. T. (1982). Interpersonal problems of Vietnam combat veterans with symptoms of posttraumatic stress disorder. J. Abnorm. Psychol. 91, 444-450.

Saigh, P. A. (1985). On the nature and etiology of traumatic stress. Behav. Ther. 16, 423-426.

Sierles, F. S., Chen, J. J., McFarland, R. E., and Taylor, M. A. (1983). Posttraumatic stress disorder and concurrent psychiatric illness: A preliminary report. Amer. J. Psychiatry 140, 1177-1179.

Sierles, F. S., Chen, J. J., Messing, M. L., Besyner, J. K., and Taylor, M. A. (1986). Concurrent psychiatric illness in non-Hispanic outpatients diagnosed as having posttraumatic stress disorder. J. Nerv. Ment. Dis. 174, 171-173.

Silver, S. M., and Iacono, C. V. (1984). Factor analytic support for DSM-III's post-traumatic stress disorder for Vietnam veterans. J. Clin. Psychol. 40, 5-14.

Stellman, J. M., Klitzman, S., Gordon, G. R., and Snow, B. R. (1987). Work environment and the well-being of clerical workers. J. Occup. Behav. 8, 95-114.

Stellman, S. D., Stellman, J. M., and Sommer, J. F., Jr. (1988a). Combat and herbicide exposures in Vietnam among a sample of American Legionnaires. Environ. Res. 47, 112-128.

Stellman, J. M., Stellman, S. D., and Sommer, J. F., Jr. (1988b). Social and behaviorial consequences of the Vietnam experience among American Legionnaires. Environ. Res. 47, 129-149.

Stellman, S. D., Stellman, J. M., and Sommer, J. F., Jr. (1988c). Health and reproductive outcomes among American Legionnaires in relation to combat and herbicide exposure in Vietnam. Environ. Res. 47, 150-174.

Stellman, J. M., Stellman, S. D., and Sommer, J. F., Jr. (1988d). Utilization, attitudes, and experiences of Vietnam Era veterans with Veterans Administration health facilities: The American Legion Experience. Environ. Res. 47, 193-209.

Stretch, R. H., and Figley, C. R. (1984). Combat and the Vietnam veteran: Assessment of psychosocial adjustment. Armed Forces Soc. 10, 311-319.

Van Kampen, M., Watson, C. G., Tilleskjor, C., Kucala, T., and Vassar, P. (1986). The definition of posttraumatic stress disorder in alcoholic Vietnam veterans: Are the DSM-III criteria necessary and sufficient? J. Nerv. Ment. Dis. 174, 137-144.

Worthington, E. R. (1978). Demographic and pre-service variables as predictors of post-military service adjustment. In "Stress Disorders among Vietnam Veterans: Theory, Research and Treatment (C. R. Figley, Ed.). Brunner/Mazel, New York. 